\title{
World Patent Practice Analysis in the Area of Energy-Efficient and Energy-Saving Technologies
}

\author{
A.R. Sadriev \\ Kazan Federal University, Kazan, 420008, Russia
}

\section{Doi:10.5901/mjss.2014.v5n18p283}

\begin{abstract}
The matter of the world economy's transition to an innovative way of development has recently obtained the central position in the life of our society. The major place in these ongoing discussions is given to the choice of priorities, which could set a powerful impetus for innovative development of economies of the single countries. One of these priority courses is energy efficiency enhancement, that is able to become a uniting principle with respect to the other priorities of innovative activities. The world patent practice in the sphere of energy-efficient technologies is being analyzed in the present article. The regularities in the activity of applicants for patent receiving in different countries worldwide are being detected. The special attention is paid to the tendencies of patent registration in the field of energy-efficient technologies in Russia. The specialization of various countries' elaboration of energy technologies of a particular target setting is being studied.
\end{abstract}

Keywords: energy-saving and energy-efficient technologies, patents for inventions, comparative patent analysis, patent specialization of the countries.

\section{Introduction}

Under the world economy's globalization and further intensification of competitive activity on the international markets of goods and services the resolution of the issue of seeking the ways of energy efficiency enhancement for the economies of various countries all over the world becomes the matter of special importance. Being able to take effective measures, capable of providing a qualitative growth of energy resources production and consumption, demands exact knowledge and clear understanding of the essence of the appropriate world trends of technological development. In this connection studies of the patent activity tendencies in different areas of energy technologies, which have taken shape in various countries worldwide, gain in particular importance [1,2]. It should be recorded, that the problem of seeking the ways of energy efficiency enhancement on different levels of national economies' management has a special place in the foreign scientists' investigations. Therefore, the leading researchers might be conventionally united in several groups.

The most numerous among them is a research group, which research and development projects are orientated on a search of energy efficiency enhancement courses for single national economies, including the consideration of the above-mentioned issue in its' branch-wise and regional projection. Analysis of the energy efficiency of the Chinese economy in terms of its' industry's various branches' restructuring and a fuel balance change is carried out in the projects by Q. Wang, Y. Zheng, S. Wu and T. Li [3]. The practice of the concrete instruments' application of the energy efficiency enhancement programs' realization is considered in the works of J. Bing and L. Rui [4]. A more extensive problem definition of the Chinese economy's energy efficiency enhancement might be traced in the studies by J.L. Hu and S.C. Wang [5]. The problem of the Chinese economy's energy efficiency enhancement from the position of regional comparisons is regarded in the researches by G.M. Shi, J. Bi and J.N. Wang. In Japan a research team headed by S. Honma and J.L. Hu focuses on the problem of energy efficiency and potential ways of its' overcoming. Within the process of the investigations conducted by the research team a comparative analysis of the forty-seven Japanese prefectures' energy efficiency had been performed [6]. In the USA analysis of the national economy's energy efficiency, energy-saving reserves revelation, energy consumption forecasts' elaboration are the core issues under consideration of the successful and productive research team, headed by J.A. Laitner [7]. The problems of the Bulgarian economy's energy efficiency occupy an eminent place in the studies of V. Grigorova [8]. The economy of Slovenia was chosen as an object of investigations in the works of S. Bojnec and D. Papler [9].

From the point of view of the cross-country appropriateness' detection the matter of energy efficiency is considered in the works of M. Flippini $и$ L.C. Hunt [10]. Analogous research was performed by a team under the supervision of C.-C. Lee [11], and either of S. Voigt [12]. Branch-wise level of cross-culture comparisons, carried out within the framework of 
finding the ways of energy efficiency enhancement, is tackled in the projects, realized by a group of researchers, headed by A. Trianni [13].

Generalizing the results of the analysis carried out in the field of accomplishment of investigations on finding the ways of energy-saving intensification and energy efficiency enhancement, it's possible to draw a conclusion about quite a wide range of research activities, conducted by scientists and experts worldwide within the framework of the problem considered. However, the surveys, where the matters of intellectual property protection in the sphere of energy-efficient technologies would be purposefully considered; unfortunately, have not got their due development.

\section{Method}

A field of research of patent activity in different countries of the world is limited by the legislation specificity in this area of activity and the peculiarities of the national patent departments' work. As a rule, a time interval from the moment of filing an application for an intellectual property object registration to obtainment of a corresponding security document lasts for no less than eighteen months. At the same time as a result of a considerable increase of applications, being filed over the recent years, a continuance of their registration term is only increasing in many developed countries of the world. Thus, in the USA in 2009-2011 about 80\% of filings for getting a patent for invention were undergoing the procedures, provided by the acting regulations for during almost five years. Taking into consideration the fact, that in the vast majority of the countries the period of validity of patents is calculated from the moment of patent application filing, not from the date of its' registration; national patent departments are able to provide information about security documents registered with a certain temporal lag only. Because of this, the information analyzed throughout the present paper is predominantly limited by the years 2011-2012.

It's worth noting, that analysis of patent activity in various countries worldwide might be carried out using several indices. Among them the most significant ones are the number of applications for intellectual property objects' registration filed during a calendar year and a number of patents, responding to them. At the same time patents might be granted for various objects of intellectual property, including inventions, industrial samples and useful models. Patents for inventions are definitive amid them. On the one hand, this is because of a more remarkable creative, engineer and scientific level of inventions, exemplifying an innovative development level of this or that country to the best extent. On the other hand, it's attributed to the fact, that patents for inventions are granted almost in every country of the world.

\section{Results}

\subsection{Energy technologies in filings for patents for inventions}

Addressing the structure of the applications filed for reception of patents for inventions, a stable tendency of the applicants' activity domination in the two major spheres of technics becomes obvious-computer technology, electrical machinery, apparatus, energy.

In 2011 world computer technology accounts for 134272 patent applications, that is 7,7\% of the total volume of claims submitted. The number of applications in the field of electrical machinery and energetics reaches 122697 claims or $7,1 \%$ of their total quantity. However, addressing the dynamics of change in the number of bids submitted for obtainment of patents for inventions, it becomes apparent, that computer technologies with the growth rate of $2,1 \%$ for the period from 2007 to 2011 concede substantially to technologies in the area of electrical machinery and energetics which, in turn, have the said index of 5,0\%. Currently, id est by 2014, the gap between these two groups of technologies had been reduced to minimum. Statistics on applications filed in 2013 for reception of patents for inventions on PCT system indirectly confirms it as well. In compliance with the data, provided by the World Intellectual Property Organization (WIPO) the largest number of them accounts right for technologies in the field of electrical machinery and energetics- 14897 claims, whilst there had been registered 14684 bids filed for patent receiving in the area of computer technologies.

The greatest activity in filing applications for receipt of security documents protecting the solutions in the sphere of electrical machinery and energetics is primarily typical for five countries, including Japan, Germany, the Republic of Korea, China and the United States of America. Over a period from 2007 to 2011 almost 80\% of the all claims submitted accounts for them. Japan is an undisputable leader among these countries, its' contribution to a total number of claims for obtainment of patents for inventions exceeds $35 \%$. 


\subsection{The Russian applicants' activity for reception of patents for energy-efficient technologies}

Addressing the statistics on patents for inventions, issued in Russia in the sphere of electrical machinery and energetics over the period from 2004 to 2010, one may find a range of regularities. Firstly, the positions of the Russian Federation in the list of applicants in the said area of technics seem to be quite humble - 4067 of claims in 2011 (table 1), what accounts for just $0,73 \%$ of their total number in the world. Secondly, for a specified period the patents were issued within five out of eight rubrics of the International Patent Classification (IPC).

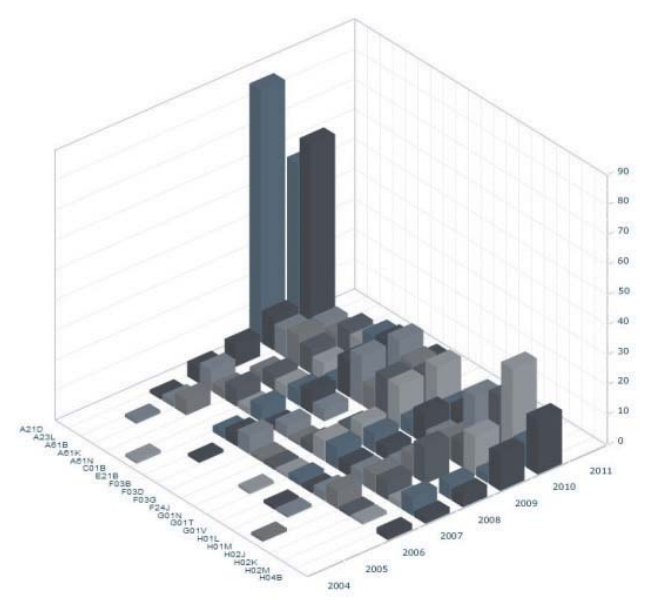

Fig. 1. Dynamics of patents issued in Russia in the sphere of electrical machinery and energetics on the IPC order over the period from 2004 to 2011

It means, that the solutions, concerning the problems of energy production or consumption to certain extent, are considered by the applicants within the framework of a rather broad range of the branches of human activities. Thirdly, the largest number of the patents issued, having a direct or an indirect concern to energy technologies, is inherent for the two major rubrics of the IPC - "A" rubric (vital human needs satisfaction) and rubric "H" (electricity). It might be well to point out that the majority of the patents were granted under the rubric " $\mathrm{A}$ ". The analysis carried out has shown that within this rubric the applicants' efforts have been primarily concentrated in subclasses A21D (flour and dough processing), A23L (preparation and processing of foods and beverages) and A61B (medical diagnosis, surgery and personal identity). Taking into account, that the " $\mathrm{A}$ " rubric is far from being a core one with respect to energy technologies, one may draw a conclusion, that in most cases the patents granted within it do not have any direct relation to energy saving and energy efficiency enhancement and only consider these issues in the context of the other processes, that tend to be more essential for it. The " $\mathrm{H}$ " rubric, which is a primary one for energy technologies, concedes evidently to the " $\mathrm{A}$ " rubric in terms of the granted patents' quantity. At the same time, in the structure of the " $\mathrm{H}$ " rubric, the subclasses «H02K» (electric cars) and «H04B» (information signals sending) have become principal for the applicants. Apart from the said rubrics, patent holders have either filed applications in the rubrics " $\mathrm{C}$ " (chemistry and metallurgy), " $\mathrm{F}$ " (engineering; lighting; heating; motors and pumps; Arms and ammunition; blasting) and "G" (physics).

Therefore, it might be concluded, that Russia's share in the global number of the patents, granted worldwide for inventions in the sphere of energy technologies, that is low as it is, may happen to be even lower. Under the maintenance of the tendency, existing in the country with the creation of the modern energy-saving and energy-efficient solutions the problem of the Russian economy's high energy consumption would be rather complicated to overcome [14].

\subsection{Different countries' of the world specialization in the development of energy technologies of the specific target functions}

In order to carry out a more thorough research of the resolutions being patented we are to turn to analysis of the relative specialization index (RSI) of one or another country in the area of technics, related to electrical machinery and energetics. By dint of this index the countries, in which applications for patents reception the branch of technics under consideration 
becomes a matter of special attention, might be detected. The whole range of energy technologies which are being patented most frequently may be subdivided into four basic groups, including solar energy technologies, wind energy technologies, geothermal energy technologies and technologies in the area of fuel cells. As for the resolutions, pertinent to solar energy, (figure 2) the British applicants clearly demonstrate their confident leadership in this sphere.

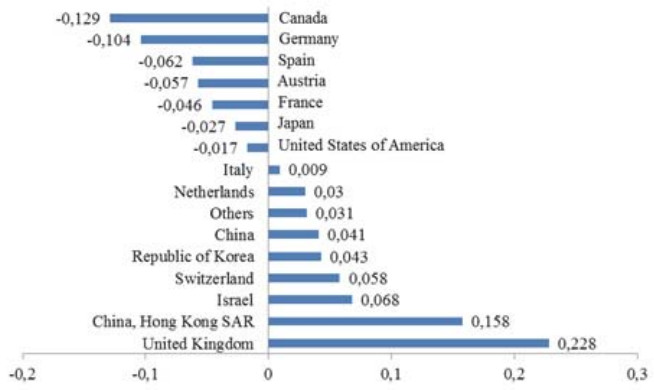

Fig. 2. Relative specialization index for patent applications for solar energy technology, 2011 [15]

The other leaders by the applications share in the field of claims for perception of patents for invention are, first of all, Hong Kong and Israel. A relatively high level of photoevoltaics technologies development in a corresponding branch of industry is either inherent for them.

The United Kingdom has also managed to provide substantial positions with regard to fuel cells development. As it may be seen from the figure three, by the share of applications for obtainment of patents for inventions it only concedes to the traditional leaders in this technological sphere - Finland and Japan.

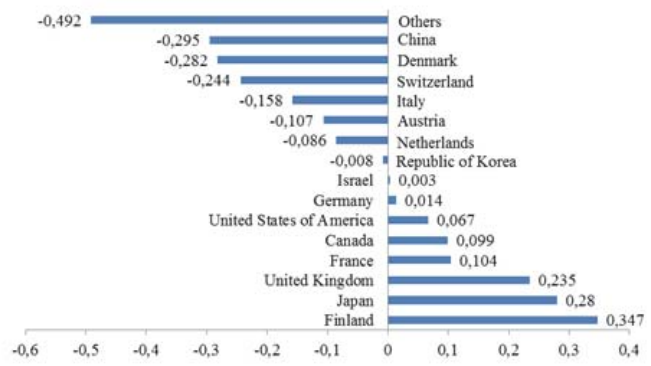

Fig. 3. Relative specialization index for patent applications for fuel cells technology, 2011 [15]

By the share of applications for registration of inventions in the sphere of windpower engineering technologies amongst the general number of applications filed to the national patent departments the strongest positions are held by Denmark, Norway and Sweden (figure 4).

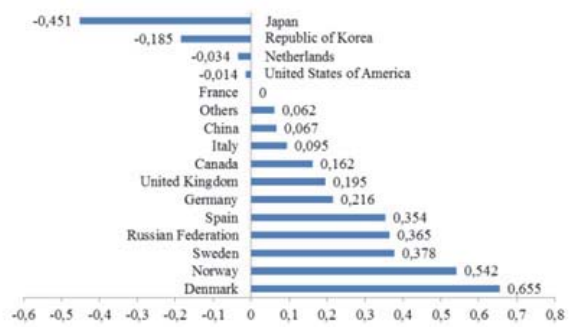

Fig. 4. Relative specialization index for patent applications for wind energy technology, 2011 [15] 
This is because of the climate peculiarities of the region, which in due time have created significant preconditions for development and wide application of technologies using the wind energy on its' territory.

However, the largest RSI values are inherent for projects in the area of geothermal energy resources. Figure 5 demonstrates, that high index values are typical for an entire range of countries. For example, for Sweden and Poland its' value is close to one, what is indicative of these countries' invertors' special attention towards the problems of energy technologies development.

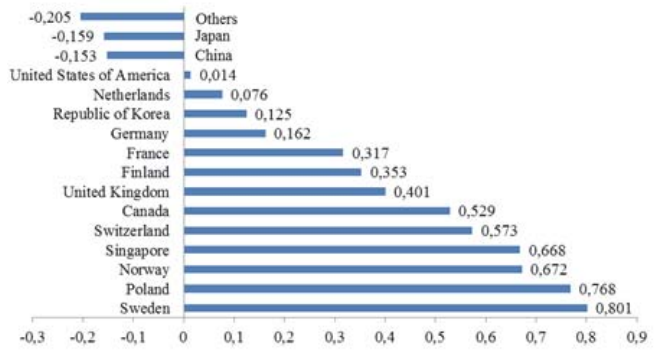

Fig. 5. Relative specialization index for patent applications for geothermal energy technology, 2011 [15]

\section{Conclusions}

Generalizing the results of the completed research, the following conclusions could be drawn. Firstly, the problems of technological development of energetics and creation of energy-efficient and energy-saving technologies occupy a special place among the innovative workings, carried out in different countries. Assumed application area of the energyefficient and energy-saving solutions, registered by declarants, tends to be rather extensive and covers various spheres of human activity, from vital human needs satisfaction to applied aspects of chemistry, physics and information technologies.

Secondly, a certain differentiation of countries by the degree of their involvement in the processes of innovative energy technologies' creation and registration is being observed. The greatest activity is demonstrated by high-income countries. On the one hand, the reason is that the authorities of these countries are characterized by a system understanding of the great importance of energy efficiency enhancement on different levels of management. On the other hand, it might be also connected with a growing rivalry on international and national markets, stimulating appearance of contemporary products and technologies, having extended resources-economy characteristics, and their further promotion.

Thirdly, in the world patent practice a certain regularity of applications filing for obtainment of patents for inventions in various areas of energy technologies had formed. The analysis conducted allowed to detect some countries' specialization in the development of energy technologies of a particular type or purpose, including, mainly, solar energy technologies, wind energy technologies, geothermal energy technologies and technologies in the area of fuel cells.

\section{Acknowledgements}

This work was funded by the subsidy allocated to Kazan Federal University for the state assignment in the sphere of scientific activities.

\section{References}

Sadriev A.R., Pratchenko O.V. 2014. Idea management in the system of innovative management // Mediterranean Journal of Social Sciences. Volume 5 (12), pp. 155-158.

Kirshin I.A. 2014. Modeling the long-term trend of accumulation of knowledge // Life Science Journal. Volume 11(6s), pp. 482-486.

Wang, Q., Zheng, Y., Wu, S., Li, T. 2011. Mechanism of energy efficiency response to industrial restructuring and energy consumption structure change // Acta Geographica Sinica. Volume 66 (6), pp. 741-749.

Bing, J., Rui, L. 2011. Economic analysis of energy efficiency in China's economy // Actual Problems of Economics. Volume 124 (10), pp. 367-372.

Hu, J.-L., Wang, S.-C., Yeh, F.-Y. 2006. Total-factor water efficiency of regions in China // Resources Policy. Volume 31 (4), pp. 217-230 
(DOI: 10.1016/j.resourpol.2007.02.001).

Honma, S., Hu, J.-L. 2013. Total-factor energy efficiency for sectors in Japan // Energy Sources, Part B: Economics, Planning and Policy. Volume 8 (2), pp. 130-136 (DOI: 10.1080/15567240903289564).

Laitner, J.A. 2013. An overview of the energy efficiency potential // Environmental Innovation and Societal Transitions. Volume 9, pp. 3842 (DOI: 10.1016/j.eist.2013.09.005).

Grigorova, V. 2013. Effective energy consumption of the Bulgarian economy // Ikonomicheski Izsledvania. Volume 22 (2), pp. 74-108.

Bojnec, S., Papler, D. 2011. Efficient energy use and renewable sources of energy in Slovenia: A survey of public perception /I Agricultural Economics. Volume 57 (10), pp. 484-492.

Filippini, M., Hunt, L.C. 2011. Energy demand and energy efficiency in the OECD countries: A stochastic demand frontier approach // Energy Journal. Volume 32 (2), pp. 59-80.

Chang, C.-P., Berdiev, A.N., Lee, C.-C. 2013. Energy exports, globalization and economic growth: The case of south Caucasus // Economic Modelling. Volume 33, pp. 333-346 (DOI: 10.1016/j.econmod.2013.04.027).

Voigt, S., De Cian, E., Schymura, M., Verdolini, E. 2014. Energy intensity developments in 40 major economies: Structural change or technology improvement // Energy Economics. Volume 41, pp. 47-62 (DOI: 10.1016/j.eneco.2013.10.015).

Trianni, A., Cagno, E., Thollander, P., Backlund, S. 2013. Barriers to industrial energy efficiency in foundries: A European comparison // Journal of Cleaner Production. Volume 40, pp. 161-176 (DOI: 10.1016/j.jclepro.2012.08.040).

Melnik A.N., Mustafina O.N. 2014. The liberalization of electricity market in Russia // Asian Social Science. Volume 10 (13), pp. $280-286$.

World Intellectual Property Indicators-2013 Edition. http://www.wipo.int/ipstats/en/wipi/ (Accessed on July 1, 2014). 